\title{
Study on Hydrologic Forecasting at the Construction Period of Datengxia Hydroproject
}

\author{
Kangming Lu \\ Bureau of Hydrology of Pearl River Water Resources Commission, Guangzhou, 510611, China \\ Correspondence: Kangming Lu (kangminglu@126.com) \\ Published: 16 September 2020
}

\begin{abstract}
To provide better service of hydrologic forecasting in the construction period of Datengxia Hydroproject that is the largest one under construction on the Pearl River, this paper focuses in analysing the characteristics of the regional floods, and reviewing the hydrologic forecasting work since starting construction, and discussing the hydrologic forecasting methods of the period not only the river closure but also the initial filling. The paper presents some practical work experiences and suitable forecasting methods on the basis of the construction schedule and the river diversion schemes. The study will conducive to improve our service ability of hydrologic forecasting and provide the important technical support of safe construction during the flood season.
\end{abstract}

\section{Introduction}

Datengxia hydroproject is the largest one under construction on the Pearl River, southern of China. After completion, the hydroproject will play an important role in flood control, shipping, power generation, Pearl River Delta water supply, irrigation, etc. (Yue, 2014).

Hydrologic forecasting is an important non-engineering measure to prevent from flood at the construction period. It is necessary to do some research on forecasting methods on the basis of the construction schedule and the river diversion schemes. These forecasting methods have provided important technical support for reasonable construction arrangement.

\subsection{Brief description of the hydroproject}

The hydroproject is located in the main stream of Pearl River which is also called West River (Wu and Zhang, 2017), about $6.6 \mathrm{~km}$ upstream from the Rainbow Bridge of Guiping City (Cheng et al., 2016). The hydrologic network of Datengxia Basin as shown in Fig. 1. The area of Datengxia catchment is $198612 \mathrm{~km}^{2}$, which accounts for $56 \%$ of the area of West River Basin. The storage capacity of the hydroproject for flood control is about 1.50 billion $^{3}$ ( $\mathrm{Li}$ and Zhan, 2018).

\subsection{Schedule of construction diversion}

The construction period of the hydroprojet is divided into two stages. The diversion standard of the longitudinal cofferdam is a 20-year return flood $\left(39300 \mathrm{~m}^{3} \mathrm{~s}^{-1}\right)$ (Zeng et al., 2013), so that it will work at both first-stage river diversion of right bank and second-stage river diversion of left bank.

The first-stage river diversion of right bank has began at September 2015, and it will last for 51 months. The construction includes the lock, the power plant of left bank, the sluices of left bank, the auxiliary dams of West River and Nanmu River. The intended completion date will be before early May 2019. The date of the river closure will be planned in November 2019.

The second-stage river diversion of left bank will begin at September 2019, and it will last for 49 months. The storage period of the first-stage project will be from February to April 2020.The intended completion date will be in December 2023. The construction will include the power plant of right bank, the sluices of right bank and the fishway.

\section{Flood characteristic and composition of Qian Reach}

The hydroproject is located in the Qian Reach of the West River. The Wuxuan Hydrologic Station has long term measured data of the reach. According to the analysis of Wux- 


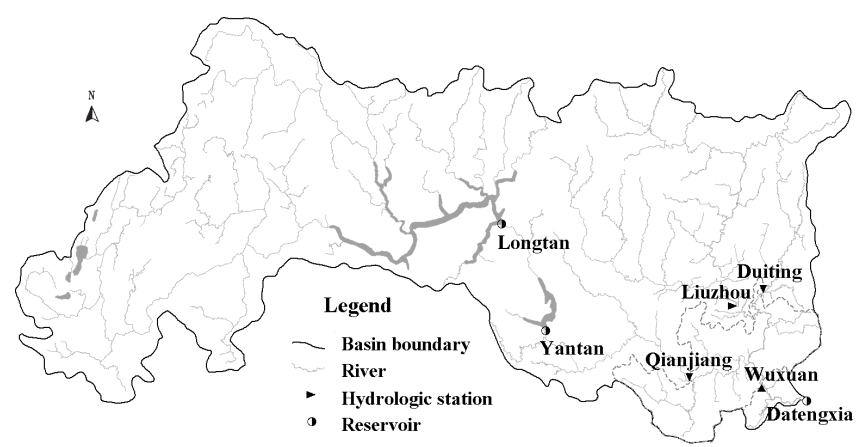

Figure 1. The hydrologic network of Datengxia Basin.

uan's data, the flood characteristic of Qian Reach is found that the flood occur last a long time with high peak and huge volume, and the occurrence probability of double flood peak can reach about $50 \%$.

The flood of Qian reach mainly comes from Hongshui River and Liu River. The stream gauging staion of Hongshui River is called Qianjiang Station. The stream gauging staions of Liu river are called Liuzhou Station and Duiting Station.

Because of the upstream reservoirs' operation (such as Longtan and Yantan) and topographic features (such as karst funnel and cenotes), the flood of Hongshui River spreads slowly and the peak is gentle. The influence of Hongshui River on flood peak in Wuxuan station is far less than that of Liu River. According to the maximum three days volume analysis of 110 floods from 2006 to 2016, the proportion of Wuxuan's floods that mainly come from Hongshui River is only $3 \%$, the proportion of Wuxuan's floods that mainly come from Liu River is $47 \%$, and the other Wuxuan's floods mainly come from both the uncontrolled area (see the dotted line area in Fig. 1) and Liu River.

The Liu River is located on the windward slope of the mountains in the northern of the Pearl River Basin. This terrain is conducive to emergence of heavy rain $(\mathrm{Ma}$ and $\mathrm{Li}$, 2013). And Liu River Basin is fan-shaped, so that the flood is rapidly gathering. That is why that Liu River is prone to multimodal floods with high peak and huge volume. The flood peak time of Wuxuan station corresponds to that of Liu River, and the proportion of flood volume of Liuzhou Station is positively correlated with that of Wuxuan Station. According to statistics, the maximum three days volume of $31 \mathrm{Wux}$ uan's floods are over 3.00 billion $\mathrm{m}^{3}$ in the past ten years. And among those floods, $74 \%$ obey the law of average travel time of the peak in the reach from Liuzhou to Wuxuan, and the maximum three days flood volume of Liuzhou accounts for $70 \%-80 \%$ of that of Wuxuan.

\section{Review of hydrologic forecasting work since starting construction}

The construction of the first-stage project has started since 2015. And during the period from September 2015 to May 2016, it was the construction period of the first-stage diversion cofferdam. The first-stage project were protected by sub cofferdams before the longitudinal and transverse cofferdams had been built to the design elevation. So we do the hydrologic work for the flood control standard of the sub cofferdams.

After the construction of cofferdams completed, we set up two temporary gauging stations on the upstream and downstream transverse cofferdams. Based on the observed data of three floods between June and August 2017, the correlation diagram had been used to work out the water level forecasting scheme of the temporary gauging stations. The forecasting scheme has been applied to the practical work since March 2018, and the result shows that the accuracy of the water level forecasting can give important technical support for the construction of the hydroproject.

\subsection{Hydrologic forecasting in the construction period of cofferdams}

During the construction period of cofferdams, we continuously worked on the flow forecasting of Wuxuan Station based on the observed data and the latest numerical forecasting of rainfall. The results indicated that both accuracy and reliability of the flood forecasting work had been satisfactory.

There was a obvious rainfall process happen in Datengxia Basin on 10-13 November 2015. A rare winter flood occurred in Qian Reach, which was the second largest flood to the previous record for that period. On the morning of 11 November, we forecasted that the flow of Wuxuan would exceed the design standard of the sub cofferdams in the drought period $\left(6720 \mathrm{~m}^{3} \mathrm{~s}^{-1}\right)$. And we informed Datengxia Company of the forecasting result and reported to the Office of Pearl River Flood Control and Drought Relief Headquarters immediately. On the morning of 12 November, we forecasted that the flow of Wuxuan would exceed $6000 \mathrm{~m}^{3} \mathrm{~s}^{-1}$ in the evening of the same day, and then issued a flood warning. The forecasting results were correct, the flow of Wuxuan reached $6000 \mathrm{~m}^{3} \mathrm{~s}^{-1}$ at 18:00 LT (BJT) of 12 November, and it exceeded $6720 \mathrm{~m}^{3} \mathrm{~s}^{-1}$ at two hours later.

From April to May 2016, there were several heavy rainfall occurred in the basin. The flood volume of Qian Reach in mid Apr. was the largest since 1936. The construction was hit by two consecutive floods that exceeded the design standard of the sub cofferdams in the flood season $\left(10500 \mathrm{~m}^{3} \mathrm{~s}^{-1}\right)$. And the extraordinary flood was happen once again in early May. The accurate forecasts were made in the morning of 10 April, 13 April and 8 May, which give important technical support for the completion of cofferdams on schedule. 
Table 1. Correlation coefficient of the fitting synthetic curves at different time intervals $n$.

\begin{tabular}{lrr}
\hline $\begin{array}{l}\text { time intervals } \\
n / \mathrm{h}\end{array}$ & $\begin{array}{r}\text { upstream transverse } \\
\text { cofferdam }\end{array}$ & $\begin{array}{r}\text { downstream transverse } \\
\text { cofferdam }\end{array}$ \\
\hline 0 & 0.915 & 0.907 \\
1 & 0.924 & 0.917 \\
2 & 0.925 & 0.929 \\
3 & 0.944 & 0.939 \\
4 & 0.953 & 0.948 \\
5 & 0.958 & 0.953 \\
6 & 0.991 & 0.990 \\
7 & 0.965 & 0.962 \\
8 & 0.968 & 0.965 \\
9 & 0.967 & 0.965 \\
\hline
\end{tabular}

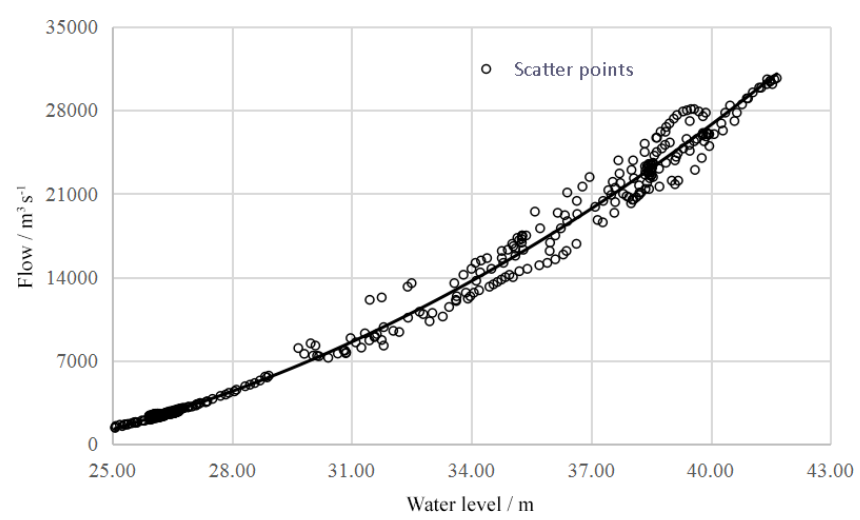

Figure 2. The scatter diagram with $T-6 \mathrm{~h}$ time flow of Wuxuan and $T$ time water level of upstream transverse cofferdam.

\subsection{Water level forecasting of upstream and downstream transverse cofferdams}

According to observed data of the temporary gauging stations from June to August 2017, we worked out a water level forecasting scheme by variable relation scatter graph. It is easily to draw the scatter diagrams with $T-n(n=1,2, \ldots, 9$ time flow of Wuxuan and $T$ time water level of upstream and downstream transverse cofferdams. Because the scattered points showed parabolic trend, then we could set up the quadratic equation with one unknown, which was fitted by the least square method. The correlation coefficient of the fitting synthetic curves were separately calculated in Table 1 . The result showed that $T-6 \mathrm{~h}$ flow of Wuxuan has the highest correlation with $T$ time water level of upstream and downstream transverse cofferdams, as shown in Figs. 2 and 3.

Considering pre-forecasting error, we should amend the forecasting result of the fitting synthetic curve. In view of the three floods in 2017 , there were still some differences in the fitting curve of each flood and the fitting synthetic curve. For example, when the flow of Wuxuan exceeded $15000 \mathrm{~m}^{3} \mathrm{~s}^{-1}$, the water level of upstream transverse cofferdam in Jul. is

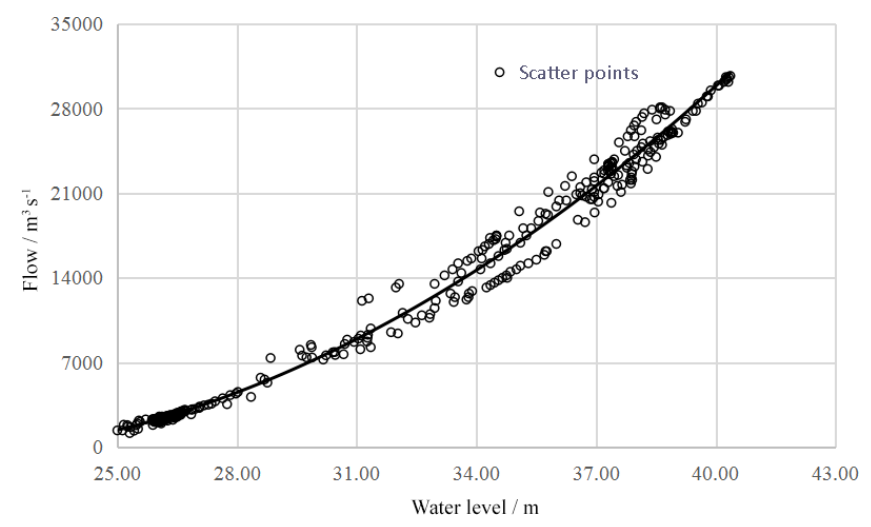

Figure 3. The scatter diagram with $T-6 \mathrm{~h}$ time flow of Wuxuan and $T$ time water level of downstream transverse cofferdam.

higher than that in Aug. in the situation of the same flow. According to analysis, the water level was related to not only current flow but also early inflow of the reach. So the forecasting result should be corrected by pre-error before issued.

The forecasting scheme has been applied to the practial work since March 2018. The absolute average forecasting error of water level of upstream and downstream transverse cofferdams were only $0.15 \mathrm{~m}$ at the foreseeable period of $24 \mathrm{~h}$. The result showed that the accuracy of water level forecast could give important technical support for the construction of the hydroproject.

\section{Hydrologic forecasting of the period not only the river closure but also the initial filling}

The flow of Qian Reach will become more complex in the period of the river closure and the initial filling, so that the forecasting scheme of Sect. 3.2 will not work any longer after demolishing the upstream and downstream transverse cofferdams. By combining hydrology method and computational hydraulics method, we attempt to find a new forecasting scheme which is suitable for the period not only the river closure but also the initial filling.

\subsection{Construction of forecasting scheme}

Because of the diversion of the longitudinal cofferdam, the water will flow though the sluices of left bank and the closure gap of right bank in the period of the river closure. According to the algorithm of ring river network ( $\mathrm{Li}$ and Wang, 2005), we can construct a computational hydraulics model of Qian Reach. The study area is generalized as upstream reach, first-stage diversion reach, second-stage diversion reach and downstream reach of the hydroproject. The sketch map of river network in the study area as shown in Fig. 4. The forecasting scheme will be applicable for different construction stages only if topographic conditions of the reaches are changed. 


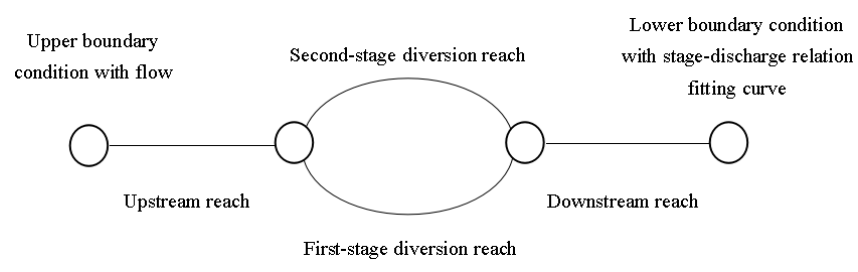

Figure 4. Sketch map of river network in the study area.

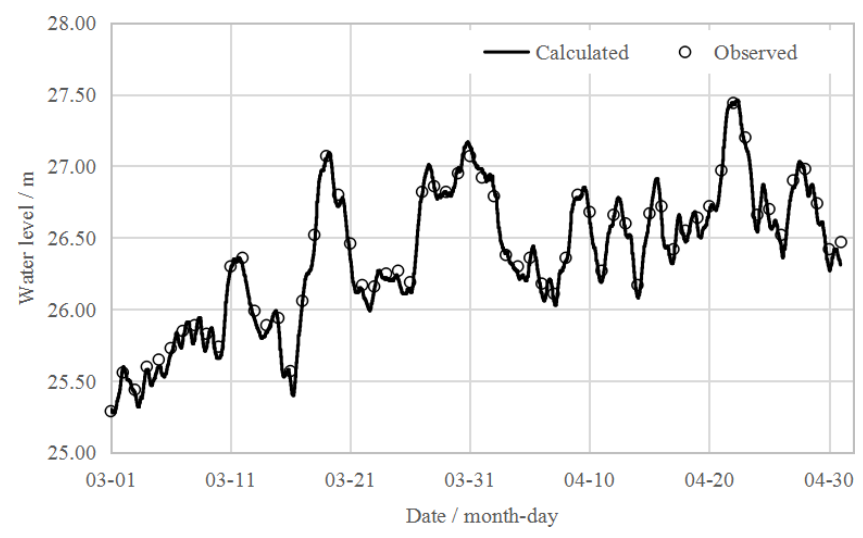

Figure 5. Water level process of forecasting and observed at upstream transverse cofferdam in March and April 2018.

\subsection{Calibration of parameters}

The parameter of the forecasting model is the roughness of each reach. According to the design flow value of the river closure, the parameters are calibrated by the observed flow of Wuxuan between 2500 and $3500 \mathrm{~m}^{3} \mathrm{~s}^{-1}$. The second-stage diversion reach should be generalized as a closed section which suppose that all the sluices of left bank are closed during the construction period of the first-stage project. The upper boundary of the model is the forecasting flow that made by hydrologic model, and the lower boundary condition is stage-discharge relation fitting curve. Through the tentative calculation, the correlation coefficients of forecasting and observed water level process should be as large as possible by constantly adjusting the roughness of each reach.

As the forecasting results in March and April 2018, the correlation coefficients of the water level of upstream and downstream of the cofferdams are all over 0.98. It is shown that the model can accurately simulate the water level process of Qian Reach, and it can be applied to water level forecasting in drought period. The water level process of forecasting and observed at upstream and downstream transverse cofferdams as shown in Figs. 5 and 6.

\subsection{Prospect of application}

The model can be applied to forecast the water level of Qian Reach in the period not only the river closure but also the initial filling by changing the generalization structure of river

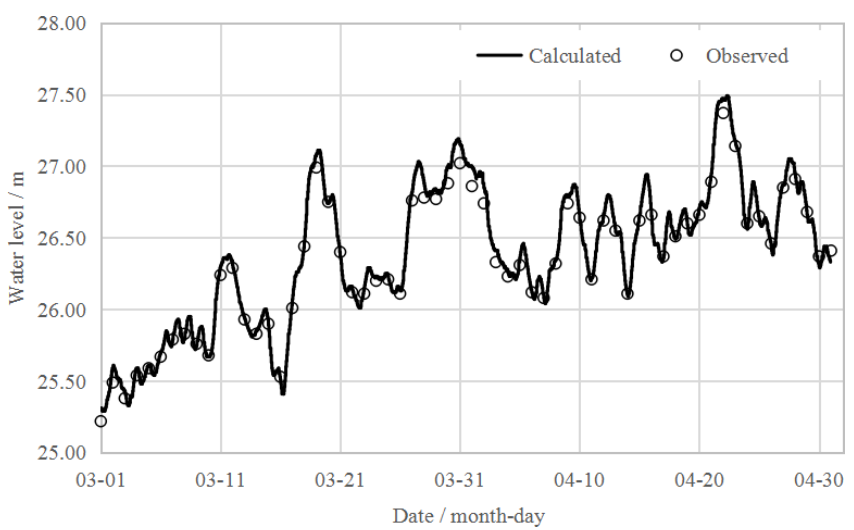

Figure 6. Water level process of forecasting and observed at downstream transverse cofferdam in March and April 2018.

network. According to the schedule, the construction of left bank project will be completed before May 2019. The sluices of left bank will work after demolishing the upstream and downstream transverse cofferdams, and therefore this reach should be generalized as weir flow with sluice control. The closure gap of first-stage diversion reach should be generalized as free weir flow, and the width of closure gap should be changed in real time. The model can be applied in the period of the river closure without changing neither topographic conditions of the other reaches nor the upper and lower boundary conditions. And after February 2020, the model can be applied in the period of the initial filling only if the first-stage diversion reach is generalized as weir flow with sluice control.

It noteworthy that two work must be actualized to ensure the hydrologic forecasting work continues. The first is that the river cross-section measurement of left bank side of longitudinal cofferdam needs to be carried out immediately after demolishing the upstream and downstream transverse cofferdams. The second is that the topographic survey of upstream reach of the hydroproject must be done when the river closure is completed. Thus the generalization of river network can match the river network topography as far as possible until the above information available.

\section{Conclusions}

This paper analyses the flood characteristic and the flood composition on Qian Reach, and reviews the hydrologic forecasting work since starting construction, and presents the water level forecasting scheme of the upstream and downstream transverse cofferdam by variable relation scatter graph. The practical application shows that the accuracy of water level forecasting can give important technical support for the construction of the Datengxia Hydroproject currently. In the end, a forecasting model suitable for the river closure and the ini- 
tial filling is discussed, which will lay the foundation of further forecasting work.

Data availability. The majority of the data presented here are from an ongoing and yet incomplete project. The datasets generated and analyzed during the current study are available from the corresponding author on reasonable request.

Competing interests. The author declares that there is no conflict of interest.

Special issue statement. This article is part of the special issue "Hydrological processes and water security in a changing world". It is a result of the 8th Global FRIEND-Water Conference: Hydrological Processes and Water Security in a Changing World, Beijing, China, 6-9 November 2018

Acknowledgements. I would like to extend my great gratitude to my graduate tutor Guangchi Li for passing on the algorithm of ring river network.

\section{References}

Cheng, Y., Li, Y., Chang, W., and Zhao, X.: Location Selection of ship lock in Datengxia hydroproject, Water Resources \& Hydropower of Northeast China, 7, 3-4, https://doi.org/10.14124/j.cnki.dbslsd22-1097.2016.07.002, 2016.

Li, G. and Wang, C.: Universal algorithm for river basin flood routing model, Journal of Hohai University (Natural Sciences), 6, 624-628, https://doi.org/10.3321/j.issn:1000-1980.2005.06.005, 2005.

Li, X. and Zhan, X.: Review on quality management of Datengxia water conservancy control project, Water Conservancy Construction and Management, 7, 4-6, https://doi.org/10.16616/j.cnki.114446/TV.2018.07.02, 2018.

Ma, X. and Li, Y.: Hydrologic analysis and calculation of Datengxia hydroproject, Water Resources \& Hydropower of Northeast China, 5, 38-40, https://doi.org/10.14124/j.cnki.dbslsd221097.2013.05.025, 2013.

Wu, Y. and Zhang, X.: Impact of Datengxia gorge water conservancy project on navigation condition, Guangxi Water Resources \& Hydropower Engineering, 4, 93-95, https://doi.org/10.16014/j.cnki.1003-1510.2017.04.029, 2017.

Yue, Z.: Promote the construction of green Pearl River by improving basin management capacity, China Water Resources, 24, 73-74, https://doi.org/10.3969/j.issn.1000-1123.2014.24.022, 2014.

Zeng, X., Ma, C., Li, Y., and Yang, S.: Discuss on construction layout and diversion design of Datengxia water conservancy control project, Pearl River, 1, 46-49, https://doi.org/10.3969/j.issn.1001-9235.2013.01.012, 2013. 